maximum maturity for the baby she was sedated and the wire left untouched; she continued to have vague contractions and backache for a further fortnight. One evening without much warning she became established in labour and before the wire could be removed she delivered herself spontaneously of a living baby weighing $3 \mathrm{lb} .3 \mathrm{oz}$. (1.4 kg.).

On examination under anaesthesia it was seen that the posterior half of the cervix had torn transversely but cleanly along the line of the wire, and the cervix had rotated forwards like a hinge, allowing the baby to escape through the rent posteriorly. The wire was removed, the cervix was repaired, and the baby survived -truly, an enterprising baby !-I am, etc.,

The Maternity Hospital, Sunderland.

D. H. JONES.

\section{Malignant Synovioma}

SIR,-Your leading article (March 16, p. 694) on "New Thoughts on Ganglia" contains a list of methods of treatment many of which would seem to be obsolete and unsatisfactory. I wish to stress the need for considering a very important differential diagnosis, namely, malignant synovioma. This was not mentioned in the editorial, and is obviously important enough to influence the choice of treatment.

A few years ago a girl of 16 years presented with a painless tense cystic swelling, about the size of a walnut, attached to the capsule and adjacent deep structures of the calcaneo-cuboid joint. It had been present for two months, but without any change in size. Clinically it appeared to be a ganglion, attached either to that joint capsule or to the sheath of peroneus longus. Radiographs were normal. When reviewed one month later there was a slight increase in size but without any local reaction; it still remained painless. Radiographs of the foot and lungs were normal. Complete excision was done, including shavings off the underlying cuboid and calcaneum bones. The swelling was cystic and the content was typical of a ganglion. The capsule was not quite as well defined as one normally finds with a ganglion, but it was possible to remove this completely. The pathological report stated the tissue to be a malignant synovioma, and the picture was certainly one of a high degree of malignancy. The pathological diagnosis was subsequently confirmed by Drs. H. L. Jaffe and A. Purdy Stout. In the absence of clinical and radiographic evidence of metastases in the regional lymph nodes and lungs respectively a wide excision of the calcaneo-cuboid joint and adjoining bones and soft tissues was performed within a fortnight of receipt of the pathological report ; stabilization of the foot was achieved by a triple arthrodesis. The follow-up period is still too short for any opinion on the success or otherwise of the treatment.

As indicated in your editorial, ganglia occur more frequently in some regions than in others. It is important to remember that any swelling which may have, or which may have had, a connexion with synovial membrane contains within it some synovial tissue which is a potential source of a very malignant variety of sarcoma. This is particularly true for swellings which occur in those sites where ganglia are rarely seen.-I am, etc.,

Sydney, Australia.

\section{S. S. Shulman.}

\section{Maternal Deaths}

SIR,-The letter on this subject from Dr. T. Magor Winstanley (May 18, p. 1345) might easily convey a most erroneous impression to those who are not conversant with obstetric statistics. Quoting from the Report on
Confidential Enquiries into Maternal Deaths in England and Wales, $1958-1960^{1}$ he writes inter alia:

"However a point of even greater import is that of the 270 deaths with an 'avoidable factor,' in 85 cases mistakes were attributed to the consultant or his junior staff. . . . Sir, writers in your columns have on many occasions pointed out that expectant mothers on leaving their G.P. obstetrician to enter the specialist unit are going from greater to lesser experience. Often this is true and has to be accepted, but when it contributes to an over- $30 \%$ mistake factor it is appalling."

Without doubt these two paragraphs might easily convey the impression that consultant obstetricians and their junior staff are perpetrating large numbers of "avoidable" obstetric errors. The simplest statistical analysis, however, shows this to be the very reverse of the truth. I will base my argument on the following facts.

(1) In England and Wales 740,715 births were recorded in 1958 ; (2) the maternal mortality rate was 0.44 per thousand; (3) the number of maternal deaths was 328 ; (4) about $70 \%$ of births occur in hospital and about $30 \%$ in domiciliary practice; (5) the Annual Report of the Royal College of Obstetricians and Gynaecologists for 1960 listed 308 Fellows and 564 Members resident in England and Wales, a total of 872 specialists of greater or lesser seniority; (6) I will assume that the number of general practitioners is 20,000 , though I am fully aware of the fact that they do not all undertake obstetrics; (7) I will assume that the practising life of both consultants and general practitioners extends over 30 years; (8) I also assume that neither the maternal mortality rate nor the "avoidable factors" (136 attributable to G.P.s and 85 attributable to specialists in the Report for 1958-60) will show any improvement over the 30-year period of 1958-87. This, fortunately, will not be the case but will ensure that the picture against the specialist is painted as black as possible.

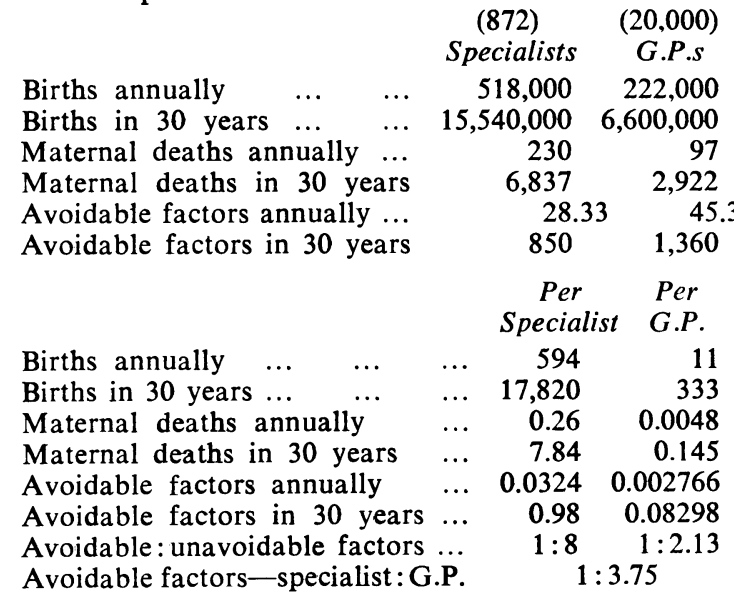

I am fully aware that the Report warns against any attempt at the direct comparison of specialist and G.P. services. For that reason I have assumed that the maternal mortality is evenly distributed, thereby crediting the G.P. with 2,922 maternal deaths of which 1,360 $(1: 2.13)$ had avoidable factors. As, however, even the strongest protagonists of G.P. obstetrics insist that he should deal with " normal" cases only, it is pertinent to ask how a G.P. can ever suffer a maternal death at all except in the gravest possible emergency out in the wilds. Furthermore it is exceedingly difficult to see where he can obtain this "greater" experience of which Dr. Winstanley speaks so confidently. Certainly the number of cases with which he deals cannot provide him with it. 